\title{
PRINCÍPIOS DA PEDAGOGIA RELACIONAL EM DUAS REGÊNCIAS DO PIBID LETRAS/ESPANHOL DA UFPR
PRINCIPLES OF RELATIONAL PEDAGOGY IN TWO CLASSES OF UFPR PIBID/SPANISH

Pedro Filipe de Lima*

\begin{abstract}
RESUMO: Este artigo visa expor as tendências pedagógicas estipuladas pelo professor doutor Fernando Becker e aponta, com base na observação de duas regências aplicadas pelos bolsistas do PIBID Letras/Espanhol da UFPR como algumas características de uma delas, a pedagogia relacional, se manifestaram nas aulas em questão - ainda que os pressupostos teóricos de Becker não tenham sido estudados pelos bolsistas, eles estiveram presentes em muitos momentos dessas regências. Concluímos que a pedagogia relacional auxilia o professor de língua estrangeira ao proporcionar-Ihe a possibilidade de ensinar os alunos com base em conhecimentos já adquiridos por eles.
\end{abstract}

Palavras-chave: PIBID; Regências; Pedagogia relacional.

ABSTRACT: This essay exposes the pedagogical tendencies explained by professor and doctor Fernando Becker and appoints, based on observations of two classes made by scholarships from UFPR PIBID Letras/Spanish, how some characteristics of one of them, the relational pedagogy, were present at these classes. It shows, based on observations of two classes made up of students from UFPR PIBID Letras/Spanish, how some characteristics of Relational Pedagogy were present. Even though Becker's writings weren't studied by the students, they still sometimes manifested his ideas in these classes. We have concluded that Relational Pedagogy helps teachers of foreign languages when it provides them with the opportunity of teaching students based on their previous knowledge.

Keywords: PIBID; Clases; Relational pedagogy.

\section{AS TENDÊNCIAS PEDAGÓGICAS DE FERNANDO BECKER: UMA SÍNTESE}

A pedagogia é a ciência que trata do educar e que tem como um de seus principais objetos de estudo a sala de aula, analisando-a desde a conduta do professor até as possíveis reações dos alunos frente aos conhecimentos a eles apresentados, apresenta uma série de vertentes e ramificações que visam compreender como se dá todo o processo anteriormente descrito.

\footnotetext{
"Graduando em Letras pela Universidade Federal do Paraná (UFPR). Bolsista do Programa Institucional de Bolsas de Iniciação à Docência (PIBID).
} 
Para Fernando Becker, doutor em Psicologia Escolar e acadêmico da UFRGS, onde também leciona, a pedagogia pode ser dividida em três grandes tendências: a pedagogia diretiva, a não-diretiva e a relacional (BECKER, 2012, p.13).

Na pedagogia diretiva, há uma clara dicotomia, pois o professor apenas ensina e o aluno apenas aprende. A apresentação do conhecimento a ser adquirido em sala é de exclusividade do professor, uma vez que o aluno é visto somente como "uma folha de papel em branco; é tábula rasa" (BECKER, 2012, p.15). Além disso, é esperado que todos os estudantes estejam sempre partindo do mesmo ponto, ou seja, saberes trazidos de casa e adquiridos fora da escola não são levados em consideração. Nesses casos, o docente também tende a ter uma rígida postura quanto a casos de indisciplina, sem considerar nuances específicas existentes em cada caso em particular. Essa tendência pedagógica está baseada numa epistemologia empirista, em que "o sujeito é totalmente determinado pelo mundo do objeto ou meio físico e social" (BECKER, 2012, p.15), por conseguinte, a sala de aula não é um lugar em que novas experiências podem ser vivenciadas, tornando-se somente um ambiente de reprodução.

A pedagogia não-diretiva, como o nome já nos sugere, busca ser 0 oposto da supracitada: para seus adeptos, o aluno já tem vários conhecimentos armazenados em sua memória, seja pelas suas vivências anteriores à escola ou pela genética adquirida graças a seus ascendentes, o que faz com a função do professor seja

[...] apenas, trazer à consciência, organizar, ou, ainda, rechear de conteúdo. O professor deve interferir o mínimo possível. Qualquer ação que o aluno decida fazer é, a priori, boa, instrutiva. [...] ele encontrará o seu caminho. O professor deve "policiar-se" para interferir o mínimo possível. (BECKER, 2012, p.17).

Ou seja, a função do professor é apenas apresentar o conteúdo, deixando que $o$ aluno adquira o conhecimento a ser atingido utilizando seus próprios meios e caminhos. Essa vertente surge da epistemologia apriorista: conforme o nome sugere - "a priori" - os docentes dessa tendência creem que o indivíduo já tem, em sua genética e bagagem histórica, conhecimentos 
advindos de sua hereditariedade e que eles transitarão naturalmente por "fases de desenvolvimento cronologicamente fixas" (BECKER, 2012, p.18), ou seja, não há o que o professor possa fazer para mudar os potenciais e talentos do aluno.

Por fim, seria correto afirmar que a pedagogia relacional busca chegar a uma espécie de equilíbrio, um meio termo: o professor apresenta um material novo para os alunos e eles devem, juntos, interagir com ele, explorá-lo e entender os seus mecanismos. Após essa primeira fase, o professor expõe perguntas ou exercícios que visem fixar ou refletir sobre a matéria apresentada. É fundamental, também, que o professor conheça seus alunos, ao menos com alguma profundidade, para que saiba como chamar a sua atenção e trazer ferramentas que tornem o novo aprendizado atrativo sob algum aspecto, pois ele crê que "professor e aluno determinam-se mutuamente" (BECKER, 2012, p.22). A epistemologia seguida por esse modelo, como o próprio nome já sugere, é a relacional (ou construtivista): o aprendizado é visto como um processo constante e contínuo e todo conteúdo novo provoca "(...) perturbações, pois traz consigo algo novo para o qual a estrutura assimiladora não tem instrumento" (BECKER, 2012 p.23). De acordo com essa epistemologia, a construção do conhecimento não tem um começo ou fim absoluto.

Por fim, Becker sintetiza todas essas informações no quadro abaixo, em que "S" significa "sujeito", "O" significa "objeto", "A" significa "aluno" e "P" significa "professor". As setas apontam para o local em que o agente passivo se encontra e, de seu lado oposto, está o sujeito que deve ser o protagonista da aula. 


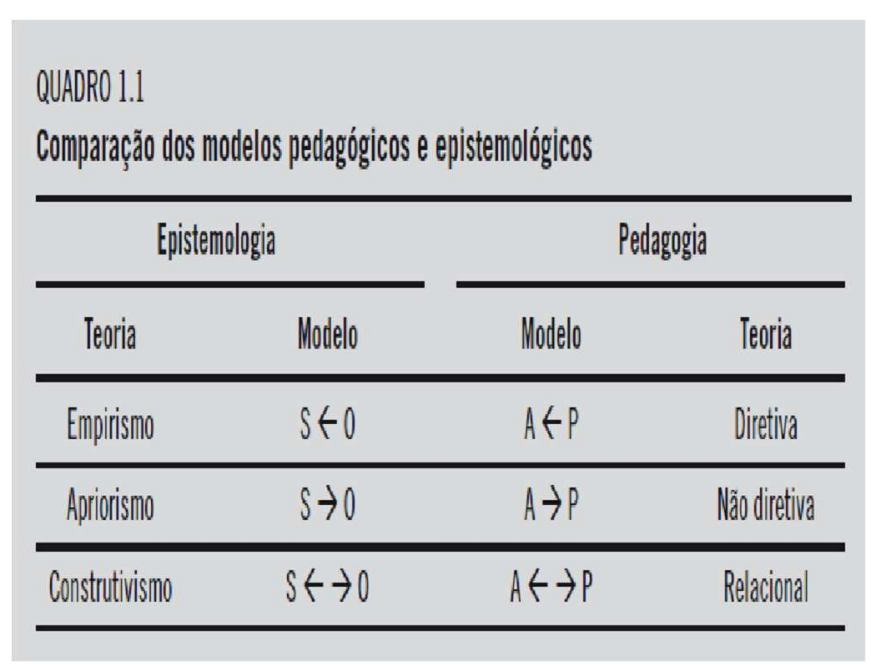

(BECKER 2012, p.26)

Nosso objetivo neste trabalho é mostrar como o conceito de pedagogia relacional proposto por Becker se manifestou em duas regências realizadas pelo PIBID Letras/Espanhol da UFPR em 2015. Ainda que o teórico não tenha sido lido pelos bolsistas do projeto como parte de sua formação acadêmica no ano em questão, seus pressupostos teóricos estiveram, de alguma forma, presentes durante as aulas realizadas.

\section{A ATUAÇÃO DO PIBID LETRAS/ESPANHOL NA UFPR}

O Programa Institucional de Bolsas de Iniciação à Docência, mais conhecido pela abreviação PIBID, é uma iniciativa do Ministério da Educação criada em 2009 e que visa valorizar e motivar a formação dos licenciandos nas universidades públicas e privadas do país (CAPES, 2014). Para tanto, os alunos recebem bolsas do Centro de Aperfeiçoamento de Pessoal de Ensino Superior, divisão do MEC conhecida como CAPES, para participar do programa, onde eles devem observar semanalmente as aulas de um professor da rede pública previamente selecionado para participar do projeto e que exerce a função de "professor-supervisor." Com o intuito de fornecer um respaldo teórico para cada um dos projetos, os bolsistas também devem realizar reuniões na universidade em que estudam, a fim de discutir o que viram nas aulas observadas, as regências a serem aplicadas e textos teóricos previamente selecionados pelo coordenador do projeto e que sempre é um 
professor da universidade em que estudam - a sua função é, pois, a de "professor-coordenador".

Atualmente, o PIBID já se encontra consolidado em grande parte do país, atuando em mais de 200 universidades e com projetos em todas as ramificações da licenciatura (Letras, Pedagogia, Química etc). Ao todo, estimase que o PIBID tenha cerca de 90 mil bolsistas no Brasil inteiro, dentre eles licenciandos, professores-supervisores e professores-coordenadores. (CAPES, 2014). Por ser um projeto de extensão que proporciona uma experiência bastante enriquecedora, o PIBID, em seu pouco tempo de existência, já apresenta uma grande produção acadêmica, em especial monografias de graduandos e dissertações de mestrado. O PIBID Letras/Espanhol, implantado na UFPR em 2010, parte de uma perspectiva bakhtiniana da linguagem, em que as línguas, mais do que um conjunto de sons sequenciais e signos que estabelecem relações entre si, também são fruto de uma profunda interação social ente os falantes do idioma em que o texto está escrito. Para Mikhail Bakhtin (2002, p.37-38),

Os processos de compreensão de todos os fenômenos ideológicos (um quadro, uma peça musical, um ritual ou um comportamento humano) não podem operar sem a participação do discurso interior. Todas as manifestações da criação ideológica - todos os signos não-verbais - banham-se no discurso e não podem ser nem totalmente isoladas nem totalmente separadas dele.

Sendo assim, o projeto sobredito parte do pressuposto de que, ao ter contato com diferentes gêneros textuais autênticos, isto é, produções que não foram criadas artificialmente para aulas de línguas estrangeiras modernas, os discentes terão não somente uma maior compreensão da língua e cultura que estão aprendendo, mas também fixarão com mais facilidade o conteúdo a ser aprendido, pois o verão em contextos reais da língua meta.

Ao trabalhar com um determinado texto, todas as regências desse subprojeto seguem um rigoroso esquema de trabalho, em que a sua análise do texto escolhido é divida em três etapas: a pré-leitura, a leitura e a pós leitura (SOLÉ, 1998, p.74).

$\mathrm{Na}$ primeira delas, evocamos o conhecimento de mundo que os alunos naturalmente carregam consigo. Sua principal finalidade é despertar a 
confiança nos educandos, para que eles se sintam capazes de ler o texto trazido pelo professor e que não deve, idealmente, ser conhecido por eles. Contudo, essa segurança também deve vir aliada à sensação de "desafio estimulante" (SOLÉ, 1998, p.92). Portanto, a função da pré-leitura é instigar os alunos para que sigam adiante. Ao trazer um manual para a sala de aula, por exemplo, o professor pode perguntar aos alunos se eles já leram algum texto do gênero, por qual motivo o fizeram ou, ainda, pedir para que eles olhem para o manual e tentem reconhecer alguma de suas características.

A segunda fase talvez seja a mais difícil, pois é o momento em que o aluno deve assimilar o novo: ao seguir essa estrutura em suas aulas, é de suma importância que o professor se mostre presente para os estudantes, para que eles não se sintam desamparados. Definir como essa fase de leitura deve ser seguida é algo difícil, pois "as situações de leitura podem ser muito variadas" (SOLÉ, 1998, p.120). Sendo assim, destacamos novamente a necessidade em conhecer os alunos com que se trabalha, seus gostos pessoais e seus objetivos na escola.

Por fim, a última etapa é aquela em que, mais do que verificar se o aluno entendeu o que leu, é preciso que ele o comprove produzindo algo baseado em sua leitura. Seja num resumo ou numa breve análise, o estudante deve ser capaz de produzir algum juízo de valor sobre o texto estudado em sala. Retomando o exemplo do manual, o professor pode, a fim de cumprir a pósleitura, pedir aos alunos para que produzam algum manual em sala.

Em 2015, o PIBID Letras/Espanhol da UFPR atuou em três escolas de Curitiba: o Colégio Paulo Leminski, localizado no bairro Tarumã, o Colégio Tiradentes, no centro da cidade, e o Colégio Rio Branco, no bairro Batel apenas nesse último foram acompanhadas aulas de Ensino Regular; no caso, turmas de Ensino Médio. Nas demais, os bolsistas vivenciaram aulas do Centro de Línguas Estrangeiras Modernas, mais conhecido por CELEM, uma iniciativa da Secretaria de Educação do Estado do Paraná existente no estado desde o final dos anos 80 (PICANÇO, 2003, p.151) e que visa ensinar gratuitamente LEMs à comunidade. ${ }^{1}$

\footnotetext{
${ }^{1}$ Desse ponto em diante, utilizarei essa abreviação para me referir a "Línguas Estrangeiras Modernas".
} 


\section{O PIBID NO CELEM: DIÁLOGOS POSSÍVEIS}

A importância do aprendizado de LEMs é inquestionável: no Brasil, indivíduos bilíngues podem ganhar até $50 \%$ a mais do que monolíngues (NOMURA, 2010) e, apesar de o português ser a sexta língua mais falada no mundo, trata-se de uma "língua periférica" (BRITTO, 2012, p.31), em que pouco conhecimento é de fato produzido por seus falantes, principalmente em comparação com as línguas inglesa e espanhola.

Portanto, é natural que o ensino de LEMs faça parte do currículo de colégios regulares e que escolas de idiomas sejam um seguimento grande do mercado brasileiro num geral. Contudo, no ensino regular, apenas a escrita e leitura são habilidades obrigatoriamente trabalhadas em outros idiomas, visto que o ensino de LEMs nessa formação visa principalmente instrumentalizar o aluno para que ele utilize outros idiomas como meio de aquisição de conhecimento, conforme constam nos Parâmetros Curriculares Nacionais dessa área da licenciatura (BRASIL, 1998, p.20). O CELEM, no entanto, tem como objetivo tornar o aluno fluente na língua meta, trabalhando as quatro habilidades: escrita, leitura, fala e compreensão auditiva. Presente em várias regiões do Estado do Paraná, o CELEM disponibiliza o ensino de várias línguas, como o espanhol, francês, inglês e alemão.

As escolas públicas são, em geral, um ambiente naturalmente multicultural, em que há um constante "cruzamento de culturas" (CANDAU, 2013, p.26): elas atendem alunos de diferentes religiões, etnias e classes sociais. Por suas aulas serem ofertadas à população em geral, o CELEM conta com mais um choque cultural: a convivência de faixas etárias diferentes, por vezes até discrepantes. É comum haver, por exemplo, numa mesma sala de aula, alunos de 10 e 50 anos. Dessa forma, esse espaço oferece um desafio ainda maior ao professor, haja vista a necessidade de encontrar diferentes formas de atingir todos esses estudantes.

Com essas características, o CELEM oferece novos horizontes e oportunidades ao PIBID em questão, uma vez que, além de ser um possível campo de atuação profissional para os alunos depois de formados, os bolsistas também devem se comprometer com o processo supramencionado de cativar 
simultaneamente alunos de diferentes idades.

\section{TRABALHANDO AS PERÍFRASES VERBAIS}

A primeira regência aqui analisada foi aplicada no dia 20 de agosto de 2015, no Colégio Paulo Leminski, por três bolsistas do PIBID Letras/Espanhol: a pedido de uma professora-supervisora do projeto, os acadêmicos tiveram que elaborar uma aula sobre perífrases verbais, conteúdo já visto pelos alunos antes desse dia e que, segundo a professora, apresentavam dificuldades contínuas. A supervisora lecionava para duas turmas: a primeira, cujas aulas aconteciam das $17 \mathrm{~h} 50$ as $19 \mathrm{~h} 20$, apresentava um perfil bastante variado, enquanto a segunda, que tinha aulas das $19 \mathrm{~h} 30$ as 20h50, era composta em sua maioria por pessoas maiores de idade.

Para trabalhar com esse conteúdo, usamos o texto "10 promesas de fin de año que nunca cumplimos", disponível no site Taringa! E que contém algumas das perífrases solicitadas pela professora, como a "ir + futuro" (por exemplo, voy a hacer) e "estar + gerundio" (por exemplo, están corriendo).

No começo da aula, fizemos perguntas que tinham como objetivo criar uma identificação entre os alunos e o texto, como, por exemplo, se eles faziam promessas no final do ano e/ou conheciam alguém que fazia. Como esperávamos, os que mais se manifestaram nesse momento foram os adolescentes e adultos, visto que partimos do pressuposto de que as crianças não entendiam muito bem essa prática. Em seguida, uma das bolsistas explicou brevemente como usar cada uma das três, enquanto outro fazia mímicas com verbos que escrevemos na lousa, com o intuito de ilustrar o explicado por ela - nesse momento, também explicamos a função da perífrase "tener que + verbo" (por exemplo, tengo que salir), que não está presente no texto. Em seguida, outra bolsista leu o texto com os alunos e pedimos para que eles destacassem, nas fotocópias que disponibilizamos, todas as perífrases que eles encontrassem. Logo após esse momento, tiramos dúvidas relacionadas ao vocabulário e algumas gírias presentes no texto.

Por sugestão da professora, também fizemos uma dinâmica para fixar a matéria: os alunos foram divididos em dois times e deviam sortear um verbo 
num saquinho e fazer também uma mímica, para que os demais tentassem acertar. Levamos verbos que tinham uma escrita e pronuncia diferentes do português, como desayunar (tomar café da manhã) e silbar (assobiar), para que os estudantes pudessem ampliar o seu léxico. Com essa brincadeira, tínhamos por intuito trabalhar com as crianças da sala, pois partimos do princípio de que elas se sentiriam mais atraídas por uma atividade lúdica. Contudo, não foi o que presenciamos: elas se mostraram bastante envergonhadas e não quiseram participar, enquanto os mais velhos foram os que mais demonstraram empolgação pela atividade.

Ao final de cada uma das duas aulas em que essa regência foi aplicada, pedimos para que ambas as turmas escrevessem em seus cadernos três promessas de final de ano, usando as três perífrases trabalhadas em classe.

Como foi uma regência feita às pressas, não elaboramos uma unidade didática específica para essa aula, ainda que a sua estrutura tenha estado presente durante todo o seu andamento.

A pedagogia relacional esteve presente durante a interação entre os bolsistas e alunos, visto que eles não aprenderam o conteúdo apenas observando uma explicação, mas sim atuando em cima. O contato com as perífrases se deu de forma contextualizada e a produção das frases ao final da aula permitiu que os alunos usassem o conteúdo aprendido no dia e os já adquiridos em aulas anteriores, principalmente o vocabulário.

\section{ARTIGOS DEFINIDOS E O ARTIGO NEUTRO: UMA REGÊNCIA SOBRE PROPAGANDAS}

A segunda regência que exporemos foi aplicada no dia 01 de dezembro de 2015, também no Colégio Paulo Leminski e o seu conteúdo foi novamente solicitado pela professora-supervisora da escola em questão: segundo seus relatos, os alunos seguiam confundindo o artigo masculino "el" com o artigo neutro "lo". - Logo, o objetivo dessa regência foi, novamente, fixar uma matéria já trabalhada previamente por ela.

Como uma das funções dos artigos definidos na língua espanhola é destacar e/ou enfatizar o teor do substantivo que o procede, decidimos usar propagandas para trabalhar o conteúdo solicitado. Sabendo que o artigo neutro 
lo tem, entre outras funções, enaltecer o adjetivo ou advérbio que o procede e que, apesar de ser uma palavra com muitas funções no espanhol, ele não pode, em hipótese alguma, preceder substantivos, supomos que o seu uso também seria recorrente no gênero textual escolhido, pois a função das propagandas é transmitir uma boa imagem de seu produto - e essa suposição se provou correta, pois encontramos muitos exemplos de propagandas que o usavam.

Como tivemos mais tempo para elaborar essa regência, pudemos produzir uma unidade didática ${ }^{2}$ e entregá-la aos alunos como parte do material a ser utilizado nessa aula, pois a seguimos passo a passo durante a regência.

Após entregarmos as unidades e as propagandas impressas, iniciamos a regência com perguntas que incentivassem os alunos a trazerem o seu conhecimento de mundo à aula, como, por exemplo, "Para que serve uma propaganda?" e "Quais são os lugares mais comuns em que as encontramos?". Pensando em especial nas pessoas mais velhas, também fizemos perguntas como "Vocês acham que as propagandas mudaram com o tempo? Por quê?". Dessa forma, pudemos captar a atenção de todos os alunos desde o começo da aula.

Em seguida, pedimos aos estudantes que olhassem para os escritos das propagandas e dissessem o que todos eles tinham em comum. Ainda que tenham demorado um pouco para chegar à resposta que queríamos, ela apareceu: "todas elas têm artigos". A partir desse elemento presente nas propagandas, pudemos trabalhar o tema da aula e também mostrar aos alunos a função do artigo $l o$, algo que os brasileiros em geral têm bastante dificuldade em aprender (FERREIRA, NOGUEIRA, 2010, p.422).

Após esse momento, pedimos para que os alunos abrissem suas unidades didáticas na página em que colocamos alguns exemplos de heterogenéricos, isto é, palavras parecidas ou idênticas em português e espanhol que tenham o mesmo significado, porém seus artigos têm gêneros opostos, como, por exemplo, a palavra leite: em português, dizemos "o leite", enquanto que em espanhol se diz "la leche". Discutimos esse conceito com os estudantes e deixamos claro que existem mais heterogenéricos do que os que

\footnotetext{
2 Tanto o texto utilizado na regência das perífrases quanto a unidade didática que elaboramos para esta aula encontram-se no site oficial do projeto, que consta nas referências bibliográficas deste artigo.
} 
Ihes mostramos e que aquelas palavras eram apenas algumas delas, para que os alunos tivessem ciência desse fenômeno linguístico.

Para finalizar a aula, pedimos aos estudantes que se dividissem em grupos e criassem propagandas usando a matéria vista em aula: os artigos definidos, o artigo neutro e os heterogenéricos estudados. Para auxiliá-los, levamos imagens recortadas, cartolinas, colas, gizes de cera, canetinhas e dicionários. Com o intuito de incentivar ainda mais o uso dos heterogenéricos, levamos várias imagens desses substantivos. Dessa forma, os alunos puderam usá-los indiretamente nas produções textuais. O trabalho didático com as propagandas foi bastante produtivo para sistematizar as dúvidas e dificuldades que os aprendentes de espanhol apresentam quanto ao uso dos artigos.

Para instigar os alunos a explorar a sua criatividade, propomos a eles uma competição entre as propagandas, de modo que a melhor ganharia um prêmio surpresa: uma caixa de chocolates para que os integrantes do grupo dividam entre si - ao final de cada apresentação, e depois da entrega dos prêmios, também distribuímos chocolates que levamos para os demais alunos.

As duas turmas demonstraram muita animação durante a aula e se empenharam bastante para a criação de suas propagandas. A maioria dos grupos foi capaz de usar os artigos definidos e o neutro em uma única propaganda, o que nos mostra que ela atingiu o seu objetivo.

Assim como na regência anterior, a pedagogia relacional se manifestou durante as interações entre bolsistas e alunos e na produção de textos (no caso, as propagandas) ao final da aula. Contudo, nessa última aula, há outra característica dessa tendência que não se manifestou explicitamente durante a primeira aula: o estranhamento causado pelos novos conhecimentos. Por não ser um artigo existente no português, muitos alunos tiveram receio em usar o 10 em suas propagandas e alguns sanaram dúvidas com os acadêmicos na fase da pós-leitura. Os heterogenéricos também foram uma faceta do espanhol que tirou os alunos de suas zonas de conforto, pois eles tendiam a se acomodar nas semelhanças entre as línguas espanhola e portuguesa e acharam "difícil" ter que lidar com mais essa diferença entre os idiomas em questão. 


\section{CONCLUSÕES}

Conforme pudemos constatar, a pedagogia relacional se manifestou em momentos pontuais nas regências aplicadas: contando com o fato de que, em ambas, os alunos já haviam trabalhado anteriormente com o conteúdo gramatical exposto, os bolsistas puderam ampliar a visão dos estudantes da língua meta utilizando textos autênticos produzidos nesse idioma e interagiram com eles em sala, assim como alunos. Dessa forma, estudantes e professores (no caso, os bolsistas) moldaram uns aos outros durante o processo de aprendizado: os bolsistas com suas perguntas e indagações e os alunos com suas respostas, que de alguma forma direcionavam a aula.

Além disso, os bolsistas levaram em consideração o perfil diversificado dos alunos, seja nas perguntas da fase de pré-leitura ou ao propor brincadeiras em sala - contudo, o público inicialmente almejado por essa última não foi atingido na primeira regência, visto que os alunos dessa faixa etária ficaram envergonhados e não quiseram participar. Baseado nesse episódio, podemos concluir que, mesmo que o professor conheça o perfil de seus educandos, toda aula está sujeita a imprevistos e está entre as suas atribuições ser capaz de lidar com eles de alguma forma, sem constranger ou censurar os educandos.

A pedagogia relacional tem, pois, um grande potencial para auxiliar professores de espanhol para lusofalantes devido ao fato de que ela visa, em toda aula, trabalhar com conhecimentos de mundo já adquiridos pelos alunos e através deles ir rumo ao novo, ao desconhecido. Como as línguas materna e a meta são muito próximas, é de suma importância marcar os limites entre ambas, e a pedagogia relaciona pode ser uma ferra particularmente eficaz para a realização desse procedimento.

\section{REFERÊNCIAS BIBLIOGRÁFICAS}

BAKHTIN, Mikhail. Estudo das ideologias e filosofia da linguagem. In:

Marxismo e filosofia da linguagem. Tradução de Michael Lahud e Yara Frateschi Vieira. São Paulo: Hucitec, 2002. p. 31-38.

BECKER, Fernando. Modelos pedagógicos e modelos epistemológicos. In: 2012. p. $13-26$

Educação e construção do conhecimento. Porto Alegre: Penso, 
BRASIL. Parâmetros Curriculares Nacionais (PCNs). Terceiro e quarto ciclos do Ensino Fundamental. MEC/SEF, 1998.

BRITTO, Paulo Henriques. Tradução e ilusão. Estudos Avançados, São Paulo, v. 26, n. 76, p. 21-27, 2012.

CANDAU, Vera Maria. Multiculturalismo e educação: desafios para a prática pedagógica. In: CANDAU, Vera Maria; MOREIRA, Antonio Flávio. Multiculturalismo: diferenças culturais e práticas pedagógicas. Petrópolis: Vozes, 2013.

CAPES. Mais de seis mil pessoas participam de encontro do PIBID. 09 dez. 2014. Disponível em: <http://capes.gov.br/sala-de-imprensa/noticias/7261mais-de-6-mil-pessoas-participam-de-encontro-para-discutir-a-formacao-e-avalorizacao-de-professores $>$. Acesso em: 25/03/2016.

ESPANHOL 1 - Apresentação. UFPR. 2011. Disponível em: $<$ http://ufpr.sistemaspibid.com.br/site/projects/12/paginas/54> . Acesso em: 25/03/2016.

FERREIRA, Claudia Cristina; NOGUEIRA, Sônia Regina. Superação das dificuldades em espanhol língua estrangeira mediada pelas múltiplas inteligências e estratégias de aprendizagem. In: SEMINÁRIO DE PESQUISA EM CIÊNCIAS HUMANAS, 8, 2010, Londrina: Eduel, 2010.

NOMURA, Maria Carolina. iG. 17 out. 2010. Disponível em: <http://economia.ig.com.br/carreiras/dominio-de-ingles-pode-aumentar-50-dosalario-de-cargos-operacionais $/ \mathrm{n} 1237729551993 . \mathrm{html}$. Acesso em: 25/03/2016.

PICANÇO, Deise Cristina de Lima. A abordagem comunicativa no Paraná e as primeiras tentativas de apropriação do novo enfoque pelos professores e autores de livros didáticos de espanhol no final da década de 80. In:

História, memória e ensino de espanhol (1942-1990). Curitiba: Editora UFPR, 2003.

SOLÉ, Isabel. Estratégias de leitura. Tradução de Cláudia Schilling. Porto Alegre: Artmed, 1998. 